\title{
The Total and Lectin-binding Proteome of Spherulin from Coccidioides posadasii
}

Thomas E. Grys ${ }^{\text {a\# }}$, Setu Kaushal ${ }^{\text {b\#}}$, Yasmynn Chowdhury ${ }^{b}$, Surendra Dasari ${ }^{c}$, Natalie M. Mitchell ${ }^{\mathrm{b}}$, D. Mitchell Magee ${ }^{\mathrm{d}}$, Janis E. Blair ${ }^{\mathrm{e}}$, Thomas V. Colby ${ }^{\mathrm{b}}$ and Douglas F. Lake $^{\mathrm{a}^{*}}$

a. Department of Laboratory Medicine and Pathology, Mayo Clinic, Phoenix, AZ, USA

b. School of Life Sciences, Mayo Clinic Collaborative Research Building, Arizona State University, Scottsdale, AZ, USA

c. Proteomics Core, Mayo Clinic, Rochester, MN, USA

d. Center for Personalized Diagnostics, Biodesign Institute, Arizona State University, Tempe, AZ, USA

e. Division of Infectious Diseases, Mayo Clinic, Phoenix AZ, USA

\# Co-first authors

Table of Contents:

Supplemental Figure S1 S2

Table S1 Attached Excel File 


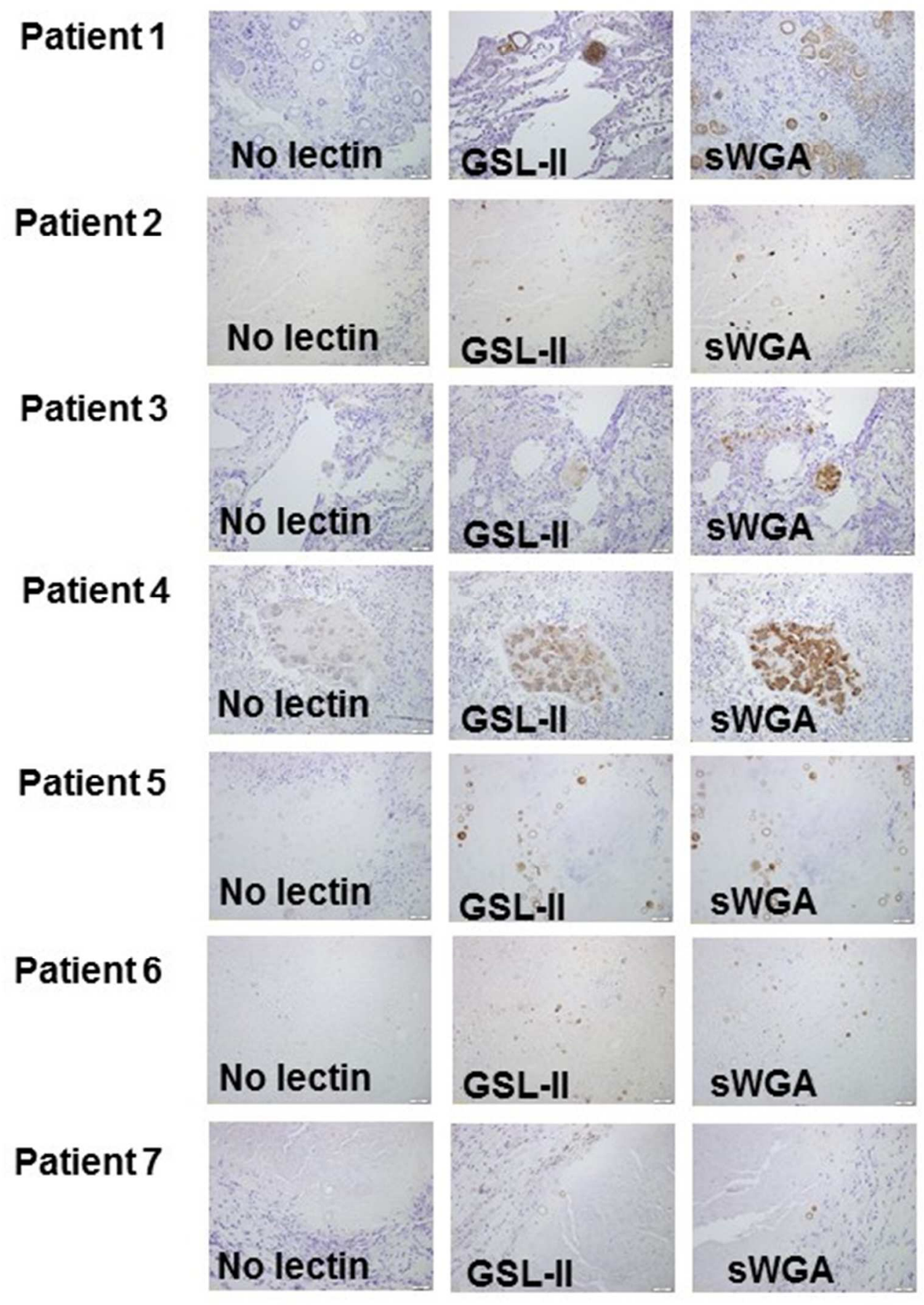

Supplemental Figure 1. Lectin-based IHC micrographs of tissue from seven Valley Fever patients. Biotinylated lectins were incubated with infected lung tissues from seven patients, as labeled in the picture and as stated in experimental procedures. Brown color indicates reactivity of lectin. GSL-II and sWGA reacted positively and specifically to endospores and spherules, and not to the adjacent human lung tissue. 


\begin{tabular}{|l|l|}
\hline Database Name & $\begin{array}{l}\text { Number of } \\
\text { Sequences }\end{array}$ \\
\hline The Broad Insitute's Coccidioides Database & 61,566 \\
\hline RefSeq Coccidioides Database & 17,312 \\
\hline Uniprot Coccidioides Database & 10,212 \\
\hline RefSeq Bovine Database & 32,221 \\
\hline RefSeq Human Database & 36,224 \\
\hline
\end{tabular}

Supplemental Table 2. Total number of protein sequences present in different databases used in this study is listed above. The final combined database has a total of 157,555 sequences. 